\title{
Seasonal prevalence of major congenital malformations in the Fylde of Lancashire 1957-1981
}

\author{
J P BOUND, ${ }^{1}$ P W HARVEY, ${ }^{2}$ AND B J FRANCIS ${ }^{3}$ \\ From ${ }^{1}$ the Department of Paediatrics, Victoria Hospital, Blackpool; ${ }^{2}$ the Department of Pathology, Royal \\ Lancaster Infirmary, Lancaster; and ${ }^{3}$ the Centre for Applied Statistics, University of Lancaster, Lancaster.
}

ABSTRACT The seasonal prevalence of major congenital malformations was studied in a prospective survey of 88449 children born in the circumscribed Fylde of Lancashire to residents there over 25 years. Ascertainment was thought to be as complete as was practically possible because cases were recorded daily by one, and for 17 years the only, paediatrician and a very high rate of necropsies was maintained. The number of malformations were classified by month of maternal last menstrual period and seasonal variation was assessed by three statistical models. Neural tube defects showed a significant seasonal variation in month of last mentrual period but not in month of birth. From May 1956 to April 1968, when the prevalence of neural tube defects was high (5.5 per 1000 total births), conceptions were significantly more common in December to May. For anencephaly alone the figures were not significant, but spina bifida and cranium bifidum were more common in March to May. From May 1968 to April 1981, when the prevalence of neural tube defects fell below the national average, the significant variations disappeared. Seasonality for spina bifida and craniun $\$$ bifidum was seen only in "singles" (cases with no other major lesion), but for anencephaly it was seet only in "multiples" (cases with other lesions). The three types of cardiac septal defect and persistenए ductus each showed a higher prevalence of conceptions at some time during May to October. I contrast the commonest group of cyanotic cases showed no such pattern but with greater numbers i winter. There was evidence of a seasonal variation for bilateral renal agenesis and for vesicoureteric reflux as ascertained.

Seasonal prevalence in an aetiological factor for certain malformations of the central nervous system, cardiac and urinary systems.

This paper examines the seasonal prevalence, using month of maternal last menstrual period, of babies with major congenital malformations born over 25 years to residents in the Fylde of Lancashire.

Seasonal changes in prevalence are one pointer to environmental factors in causation, and interest in them has continued since the demonstration by McKeown and Record ${ }^{1}$ in 1951 that more cases of anencephaly were born in autumn and winter. However, a modern paediatric textbook ${ }^{2}$ discussing seasonal variations states: "conflicting reports have come from different regions in one country and from different countries, so that much more information is required".

Contradictions may arise for several reasons. Firstly, the inevitable selection of cases in hospital series on which some reports have been based. ${ }^{3}$ Secondly, inadequate ascertainment may occur in population studies from reliance on notification of cases. The resultant problems of under-reporting and inconsistencies in diagnosis have been discussed for central nervous system malformations. ${ }^{4}$ The particular difficulties with cardiac malformations where many cases are not recognisable at birth were outlined by Hay. ${ }^{5}$ Another source of inadequate ascertainment is a low rate or poor quality of necropsies, especially for perinatal deaths where malformations may be otherwise unsuspected or misdiagnosed. It has been shown that the prevalence of cardiac malformations fell from 6.8 to 5.8 per 1000 total births if lesions in stillbirths, which were unrecognisable without necropsy, were excluded. ${ }^{6} \mathrm{~A}$ third reason for contradictions is the use of date of birth for studying seasonal prevalence, ${ }^{37}$ when variable lengths of gestation may cause inaccuracies. It has been shown that significantly more babies with cardiac malformations than controls have short gestations. ${ }^{8}$ Fourthly, in conditions with multifactorial aetiology, one factor which could be seasonal may assume particular importance over another in a given area. 
In this investigation we attempted to get as complete an ascertainment of major malformations in a population as is possible in practice and to eliminate problems caused by varying lengths of gestation.

\section{Methods}

Major malformations were studied among babies born to mothers who lived in the most populous part of the Fylde of Lancashire. This is a well demarcated area approximately $24 \mathrm{~km}$ by $13 \mathrm{~km}$, bounded on three sides by water barriers. The fourth, landward, border is in sparsely populated country (fig. 1). The population is concentrated around the coast and has increased from about 250000 to over 300000 during the period of study. Blackpool is situated centrally on the west coast. In the north the main urban areas are Fleetwood, Thornton-Cleveleys and Poulton-leFylde, and in the south, Lytham St Annes and Kirkham. The remainder of the district consists of rich farming land.

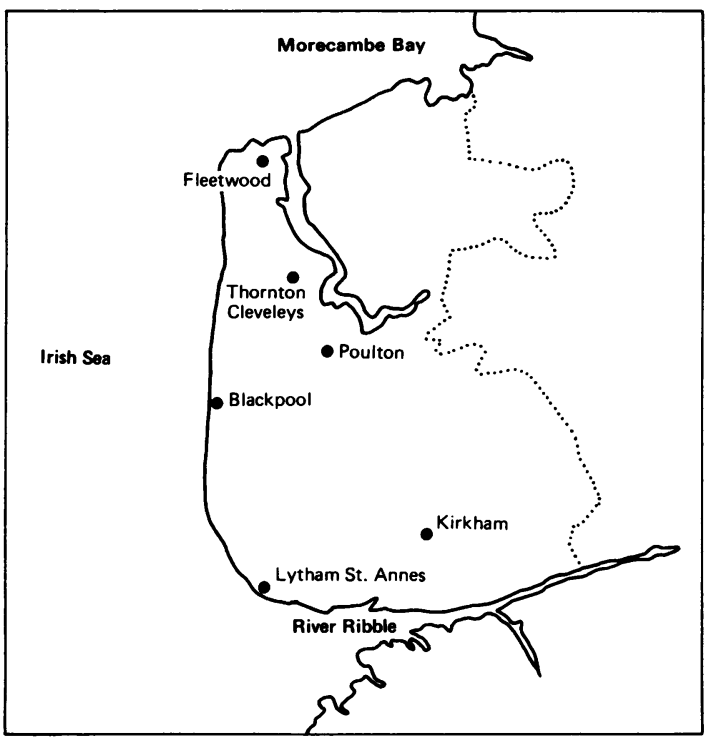

Fig 1 The Fylde of Lancashire

The district is $\mathbf{5 0}$ miles from the nearest University referral centre and medical services are based on a single district general hospital (Victoria), so that one doctor was able personally to collect data systematically on a day to day basis. The numbers of live births, stillbirths and neonatal deaths were notified to us by the medical officers of health and after 1974 by the community physician. There were 88449 births in the 25 years.

Babies studied were those born in the Fylde to residents there between 1 January 1957 and 31 December 1981. Cases of malformations in babies born during this period were collected until 31 December 1986, so that there was a minimum follow up of 5 years. Major malformations were ascertained from: (1) necropsies, (2) the daily practice of one paediatrician, and (3) in later years, the local obstetricians' records of pregnancy terminations.

A very high rate of necropsies, all by consultant pathologists, of stillbirths and all children dying up to 15 years of age was maintained throughout the 25 years. After 1957 arrangements for necropsies of babies stillborn at home were facilitated by the continuation of procedures introduced for local participation in the British Perinatal Mortality Survey. Ninety three per cent of all perinatal deaths in the area were examined, wherever they were born. The number of necropsies was checked against the notified deaths and information obtained from midwives and doctors about any visible malformation in the very small number of cases not examined by the pathologists. Necropsy reports of all Coroners' cases were received.

Terminations of pregnancy because of antenatal diagnosis of a serious malformation were carried out from 1979. There were only four such cases, all neural tube defects.

For 17 years the great majority of cases of major malformations were seen by one paediatrician (JPB) in his practice, which included full charge of neonates from the outset. He attended necropsies whenever possible and always reviewed cases with the pathologists. Members of the medical and nursing professions were aware of the study and were encouraged to inform him of children with lesions which might have escaped his attention. He visited the general practitioner maternity units at least weekly. In addition outpatient clinics were held not only at Victoria Hospital but also in the north (Fleetwood) and south (Lytham) of the district enabling good liaison with general practitioners. Further, regular consultative clinics were held with the local authority doctor responsible for the infant welfare and school medical services in Blackpool.

Victoria Hospital has a department of cardiology and a children's clinic was held by the cardiologist and paediatrician together. Complete recording of cardiac malformations presenting after the neonatal period was thus facilitated and diagnoses were constantly updated where necessary. 
In the last 8 years of the study a second paediatrician cooperated fully in reporting cases seen in his practice only. These were few in number as neonatal work was completely shared and JPB continued to organise the combined cardiac clinic.

Babies with multiple malformations were counted under each major lesion present. The following lesions were not recorded: inguinal and umbilical hernias, hypospadias, undescended testes, hydrocele, talipes, polydactyly, syndactyly, accessory auricle, naevi.

For some analyses cases of neural tube defect were divided, as in a recent American study, ${ }^{9}$ into "multiples" with one or more additional major lesions, and "singles" with no other lesions or only those considered secondary to the neural tube defect. Secondary lesions included other central nervous system defects, talipes, dislocation of the hip, contractures, spine and rib defects and lung and adrenal hypoplasia.

Classification of cardiac lesions was based on the scheme of the International Society of Cardiology. ${ }^{10}$ In addition cases of uncomplicated ventricular septal defect were divided into clinical and proven. Clinical ventricular septal defect was diagnosed from the presence of a typical murmur with normal chest $\mathbf{x}$ ray and electrocardiogram. Fewer cases fell into this category after the introduction of echocardiography in the early seventies, which enabled many small defects to be visualised without disturbing the infant.

Uncomplicated persistent ductus arteriosus was distinguished from delayed closure of the ductus in premature and small for dates babies. ${ }^{11}$ Occasionally a patent ductus in one of these two groups of low birth weight babies required surgical treatment before the distinction could be made clinically. Therefore our category of persistent ductus was restricted to babies with a gestation of 37 weeks or more and a birth weight over $2500 \mathrm{~g}$.

The antenatal notes of mothers giving birth to babies with malformations were studied and, in particular, the month of the last menstrual period was noted. The month was almost always recorded even when sometimes the day of onset was not recollected.

Data on the month of last menstrual period and month of birth was also collected for all hospital births for a selection of years over the period of the study. For two early years of the study, data were also collected on month of birth for all births occurring in the Fylde. These data sets provided information on any potential seasonal variability in the Fylde population of births. Hospital births represented 33\% of all births in 1959 , increasing to $93 \%$ of all births in 1981.

\section{STATISTICAL METHODS}

Early methods for detecting seasonality in epidemiological data have relied almost exclusively on two methods: the simple $\chi^{2}$ test for heterogeneity and a test devised by Edwards. ${ }^{12}$ Both methods have been criticised; the former for its failure to utilise information in neighbouring months ${ }^{12}$ and the latter for the poor performance of the test with small samples. ${ }^{13}$ Edwards' method has been extensively studied, and many modifications to the test have been suggested, both to extend its generality ${ }^{14}$ and to improve its small sample properties. ${ }^{1516}$ Many of the latter modifications have assumed a multinomial distribution, modelling the probability of monthly occurrence by a linear function. Recent work ${ }^{17}$ has suggested a linear model for the rate of the underlying process; we extend this idea by assuming an underlying Poisson distribution and a log-linear model for the monthly rates. These assumptions are natural for the data, and provide (through the theory of generalised linear models) ${ }^{18}$ a well established inferential framework for the examination of hypotheses. We also explored a variety of seasonality models, allowing for cyclical effects other than six months.

The observed malformations were first classifie $\mathbb{R}$ either by month of last menstrual period or b\$ month of birth. We assume for the time being that the total number of births in the population shows no evidence of seasonality. If no seasonality is present in the malformation under consideration, then the true underlying rate of occurrence per month is $\overrightarrow{0}$ constant, and the observed counts will have a Poisson distribution. If seasonality is present, then the underlying monthly rates will vary, and can be modelled. The standard method of analysing Poisson counts is through the log-linear model. Let $Y_{i}, i=1, \ldots, 12$ be the monthly counts for a malformation. Then the model of no seasonality is

$$
\begin{aligned}
& \log \left(\mu_{\mathrm{i}}\right)=\alpha \\
& \text { with } \mathrm{E}\left(\mathrm{Y}_{\mathrm{i}}\right)=\mu_{\mathrm{i}}
\end{aligned}
$$

and $\mathrm{Y}_{\mathrm{i}} \sim$ Poisson $\left(\mu_{\mathrm{i}}\right)$

The $\mu_{\mathrm{i}}$ is the expected number of counts in month $\mathrm{i}$.

We consider three models of seasonality:

(1) The two rate model

$$
\begin{array}{rlrl}
\log \left(\mu_{\mathrm{i}}\right) & =\alpha_{1} & \mathrm{i}=\mathrm{j}, \mathrm{j}+1, \ldots ., \mathrm{j}+\mathrm{k}-1 \\
& =\alpha_{2} & \mathrm{i}=\mathrm{j}+\mathrm{k}, \ldots ., 12,1, \ldots, \mathrm{j}-1
\end{array}
$$

This model assumes two underlying monthly rates of occurrence, one high and one low, and each for a consecutive period of calendar months. The first period starts in month $\mathrm{j}$ and is of length $\mathrm{k}$ months; the second period starts in month $j+k$ and lasts for $12-k$ months. The parameters $\alpha_{1}, \alpha_{2}, \mathrm{j}$ and $\mathrm{k}$ are estimated from the data. 


\section{(2) The Sin model}

$$
\log \left(\mu_{i}\right)=\lambda_{0}+\lambda_{1} \sin \left(x_{i}+\varpi\right)
$$

where $x_{i}$ is the month number i multiplied by $30^{\circ}$, $\sigma$ is the start of the cycle in degrees, and $\lambda_{0}$ and $\lambda_{1}$ are unknown parameters to be estimated. Here, the underlying monthly rate of occurrence varies smoothly, showing a six month period of increase, followed by a six month period of decrease. If $\lambda_{1}$ is zero, then the model reverts to that of no seasonality.

\section{(3) The Sin squared model}

$\log \left(\mu_{\mathrm{i}}\right)=\lambda_{0}+\lambda_{1} \sin \left(\mathrm{x}_{\mathrm{i}}+\varpi\right)+\lambda_{2} \sin ^{2}\left(\mathrm{x}_{\mathrm{i}}+\varpi\right)$ where $x_{i}$ and $w$ are defined as before. For this model, the underlying monthly rate of occurrence still varies smoothly, but follows a more complex pattern of increases and decreases. A version of this model with the counts transformed to approximate normality was suggested by Sandahl, ${ }^{19}$ who recommended it for the detection of asymmetrical periodic changes.

Each method has its advantages and disadvantages. The two rate model has the advantage that the model is easily interpreted, but it may not be a realistic representation of the underlying process. The sin model has a smooth variation in rate over the 12 months, but the assumption of six months of increase followed by six months of decrease may not be appropriate; important cyclical effects other than six months may well be missed. The sin squared model avoids this problem by adding a squared sin term to the model allowing for asymmetrical changes over the year. The estimated function produced by this method, however, is often difficult to interpret, and can have multiple maxima over the 12 month period.

For a given set of data, it is possible that certain models may show significant results and others nonsignificant results. This indicates that certain of the models are more effective at detecting certain types of periodicity compared with others.

The parameters for all the above models were estimated using the Poisson regression facility of the GLIM@ statistical package. ${ }^{20}$ Maximum likelihood estimates of the parameters were found by a combination of GLIM model fitting and grid search techniques. For the two rate model, this procedure involved fitting a separate model to estimate $\alpha_{1}, \alpha_{2}$ and the $\log$ likelihood for every combination of $(j, k)$ over a grid of all possible values of $j$ and $k$. The values $\left(j_{\max }, k_{\max }\right)$ of $j$ and $k$ which gave the maximum value of the log likelihood over the grid were taken as the maximum likelihood estimates of $j$ and $k$. For the sin and sin squared models, a one dimensional grid with $\sigma$ taking the values $0^{\circ}, 30^{\circ}, \ldots, 330^{\circ}$ was chosen and a similar procedure was used.
The deviance (minus twice the log likelihood) of the estimated model of seasonality was then subtracted from the deviance produced by the model of no seasonality to give a likelihood ratio test statistic. For the sin (and the sin squared) models, we can fix $\varpi$ and $\lambda_{1}$ (and $\lambda_{2}$ ) at zero to obtain the model of no seasonality; the test statistic is therefore approximately distributed as $\chi^{2}$ on two (and three) degrees of freedom if the model of no seasonality holds. For the two rate model, we can fix $\mathrm{j}$ and $\mathrm{k}$ at 0 to obtain the model of no seasonality, but the parameters $\mathrm{j}$ and $\mathrm{k}$ then lie on the boundary of the parameter space, and regularity conditions for the likelihood ratio test are violated. For this model, the test statistic under the hypothesis of no seasonality is therefore not $\chi^{2}$ distributed, and simulations of the distribution are necessary. The results of a series of simulations of 1000 trials based on constant monthly Poisson rates of $\mathbf{3 0}$ cases every 25 years increasing in steps of 30 up to a maximum of 240 cases every 25 years, produced no evidence of the distribution of the test statistic being related to the underlying Poisson mean. The mean value produced for the 95 th percentile was $10 \cdot 34$; that for the 99th percentile was 13.89 and that for the 99.5th percentile was $15 \cdot 36$. These values were used in subsequent testing.

All three models were applied both with and without allowing for seasonal variation in the total numbers of births in the study population. The procedure when allowing for such variations involved determining $\mathbf{P B}_{\mathrm{i}}(\mathrm{i}=1, \ldots ., 12)$, a suitable monthly classification of all births in the population under consideration. In this analysis, we used hospital births from 1979 to 1981 to represent the overall pattern of births in the Fylde. These data, which represent $92 \%$ of all births, were classified both by month of last menstrual period and by month of birth to provide suitable values for the $\mathbf{P B}_{\mathrm{i}}$ (depending on whether the analysis was on malformation classified by month of last menstrual period or birth month). For each of the models, an extra term $\log \left(\mathbf{P B}_{\mathrm{i}}\right)$ is included, with a fixed regression parameter of unity. For example, the sin model becomes

$$
\log \left(\mu_{\mathrm{i}}\right)=\log \left(\mathrm{PB}_{\mathrm{i}}\right)+\lambda_{\mathrm{o}}+\lambda_{1} \sin \left(\mathrm{x}_{\mathrm{i}}+\boldsymbol{\sigma}\right) \mathrm{Y}_{\mathrm{i}} \sim
$$$$
\text { Poisson }\left(\mu_{\mathrm{i}}\right)
$$

This model is compared to a modified "no seasonality" model

$$
\log \left(\mu_{\mathrm{i}}\right)=\log \left(\mathrm{PB}_{\mathrm{i}}\right)+\lambda_{\mathrm{o}}
$$

\section{Results}

The total prevalence of major malformations over 25 years is shown in table 1 . The prevalence of cases diagnosed up to the age of 5 years, the minimum follow up for children born at the end of the survey, is 
Table 1 Prevalence of some common major malformations in the Fylde 1957-81

\begin{tabular}{|c|c|c|c|c|}
\hline \multirow[b]{2}{*}{ Malformation } & \multicolumn{2}{|c|}{$\begin{array}{l}\text { Ascertained up to } \\
\text { age } 5 \text { years }\end{array}$} & \multirow[b]{2}{*}{$\begin{array}{l}\text { Ascertained } \\
\text { later }(n)\end{array}$} & \multirow{2}{*}{$\begin{array}{l}\text { Total } \\
\text { prevalence } \\
\text { per } 1000 \\
\text { births }\end{array}$} \\
\hline & $n$ & $\begin{array}{l}\text { Prevalence } \\
\text { per } 1000 \\
\text { births }\end{array}$ & & \\
\hline $\begin{array}{l}\text { Anencephaly } \\
1957-68 \\
1969-81\end{array}$ & $\begin{array}{r}129 \\
40\end{array}$ & $\begin{array}{l}2.74 \\
0.97\end{array}$ & - & $\begin{array}{l}2.74 \\
0.97\end{array}$ \\
\hline $\begin{array}{l}\text { Spina bifida cystica and cranium bifidum } \\
1957-68 \\
1969-81 \\
\text { Uncomplicated congenital hydrocephalus } \\
\text { Down's syndrome } \\
\text { Congenital microcephaly }\end{array}$ & $\begin{array}{r}131 \\
69 \\
34 \\
124 \\
16\end{array}$ & $\begin{array}{l}2 \cdot 78 \\
1.67 \\
0 \cdot 38 \\
1.40 \\
0 \cdot 18\end{array}$ & $\begin{array}{l}- \\
- \\
-\end{array}$ & $\begin{array}{l}2 \cdot 78 \\
1.67 \\
0 \cdot 38 \\
1.40 \\
0 \cdot 18\end{array}$ \\
\hline $\begin{array}{l}\text { Ventricular septal defect uncomplicated } \\
\text { Ostium secundum atrial septal defect } \\
\text { Ventricular septal defect with right ventricular outflow obstruction } \\
\text { Endocardial cushion defect } \\
\text { Persistent ductus arteriosus } \\
\text { Coarctation of aorta } \\
\text { Transposition of great arteries } \\
\text { Aortic stenosis } \\
\text { Pulmonary stenosis, isolated } \\
\text { All congenital heart disease }\end{array}$ & $\begin{array}{r}165 \\
59 \\
50 \\
42 \\
30 \\
36 \\
31 \\
22 \\
20 \\
579\end{array}$ & $\begin{array}{l}1 \cdot 87 \\
0 \cdot 67 \\
0 \cdot 57 \\
0 \cdot 47 \\
0 \cdot 34 \\
0 \cdot 41 \\
0 \cdot 35 \\
0 \cdot 25 \\
0 \cdot 23 \\
6 \cdot 55\end{array}$ & $\begin{array}{r}4 \\
10 \\
0 \\
0 \\
9 \\
2 \\
0 \\
5 \\
1 \\
44\end{array}$ & $\begin{array}{l}1.91 \\
0 \cdot 78 \\
0 \cdot 57 \\
0 \cdot 47 \\
0 \cdot 44 \\
0 \cdot 43 \\
0 \cdot 35 \\
0 \cdot 31 \\
0 \cdot 24 \\
7 \cdot 04\end{array}$ \\
\hline $\begin{array}{l}\text { Diaphragmatic hernia } \\
\text { Exomphalos } \\
\text { Oesophageal atresia } \\
\text { Intestinal atresia } \\
\text { Anorectal anomalies }\end{array}$ & $\begin{array}{l}36 \\
39 \\
41 \\
25 \\
57\end{array}$ & $\begin{array}{l}0 \cdot 41 \\
0 \cdot 44 \\
0 \cdot 46 \\
0 \cdot 28 \\
0 \cdot 64\end{array}$ & $\begin{array}{l}\bar{E} \\
\overline{-}\end{array}$ & $\begin{array}{l}0 \cdot 41 \\
0 \cdot 44 \\
0 \cdot 46 \\
0 \cdot 28 \\
0 \cdot 64\end{array}$ \\
\hline $\begin{array}{l}\text { Bilateral renal agenesis } \\
\text { Unilateral renal agenesis } \\
\text { Renal hypoplasia } \\
\text { Polycystic kidneys } \\
\text { Hydronephrosis (excluding cases secondary to spina bifida) } \\
\text { Primary vesicoureteric reflux } \\
\text { Duplex kidneys }\end{array}$ & $\begin{array}{l}24 \\
28 \\
23 \\
23 \\
69 \\
62 \\
23\end{array}$ & $\begin{array}{l}0 \cdot 27 \\
0 \cdot 32 \\
0 \cdot 26 \\
0 \cdot 26 \\
0 \cdot 78 \\
0 \cdot 70 \\
0 \cdot 26\end{array}$ & $\begin{array}{r}0 \\
2 \\
1 \\
1 \\
25 \\
34 \\
21\end{array}$ & $\begin{array}{l}0 \cdot 27 \\
0 \cdot 34 \\
0 \cdot 27 \\
0 \cdot 27 \\
1.06 \\
1.09 \\
0 \cdot 50\end{array}$ \\
\hline $\begin{array}{l}\text { Cleft lip with or without cleft palate, 1962-81 } \\
\text { Isolated cleft palate, 1962-81 } \\
\text { Congenital dislocation of hip } \\
\text { Reduction deformities of limbs }\end{array}$ & $\begin{array}{l}67 \\
48 \\
99 \\
55\end{array}$ & $\begin{array}{l}0 \cdot 96 \\
0 \cdot 68 \\
1 \cdot 12 \\
0 \cdot 62\end{array}$ & $\begin{array}{l}- \\
-\end{array}$ & $\begin{array}{l}0 \cdot 96 \\
0 \cdot 68 \\
1 \cdot 12 \\
0 \cdot 62\end{array}$ \\
\hline
\end{tabular}

also recorded. The difference between the two rates is a feature of cardiac and particularly of urinary system malformations. Table 2 gives the observed number of cases for each malformation classified by month of last menstrual period. Table 3 shows the same cases classified by month of birth for malformations which showed a significant variation in month of last menstrual period. Congenital dislocation of the hip was also included in table 3 because some possible aetiological factors operate in late pregnancy. For certain malformations, the data on last menstrual period have been further subdivided into two periods of 12 and 13 years because a sudden significant drop in the prevalence of anencephaly in the Fylde among conceptions after 1967 had been shown previously. ${ }^{21}$

Table 4 shows the pattern of hospital births for a selection of years over the study period, classified by month of last menstrual period and month of birth respectively. Table 4 also shows the pattern of all births for two years early in the study period, classified by month of birth. We used these data to determine whether any seasonality in all births in the Fylde was present. To this end, we analysed the hospital births using the three seasonality tests described earlier. For the hospital births classified by last menstrual period (fig 2), only one year (1976) showed a significant seasonal variation on the sin test, with a peak month of September. No other years showed a significant seasonal effect. For hospital births classified by month of birth, 1979 was the only year to show a significant seasonality effect, with a peak month of October. No consistent seasonal pattern is therefore observable in the births of Fylde residents whether last menstrual period or birth month is analysed. Finally, we examined the representativeness of hospital births compared to all births in the early years of the study. Using the three seasonality tests, data on hospital 


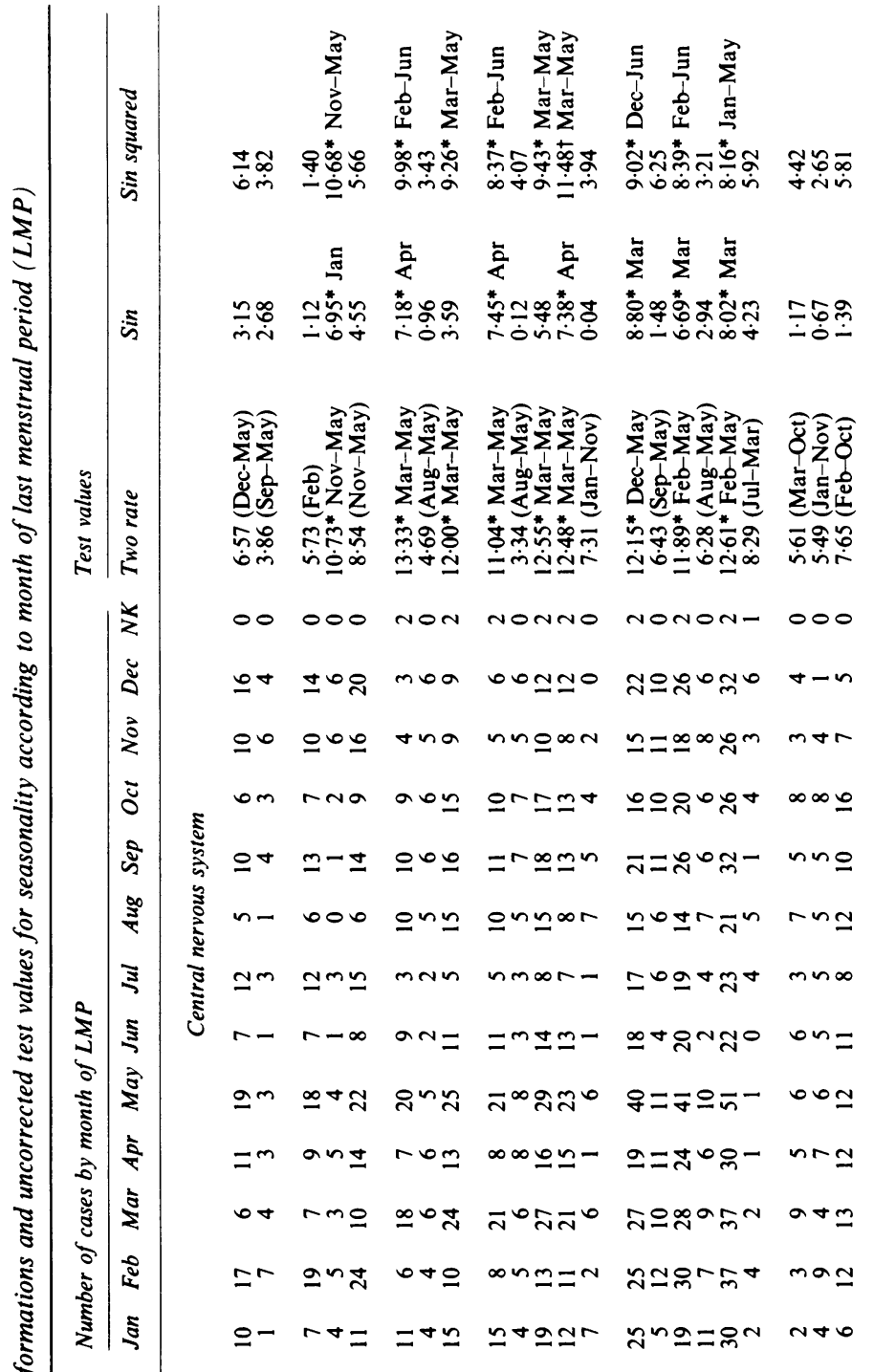

\section{¿ัष

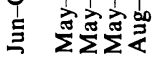

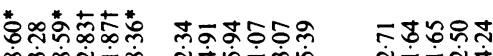

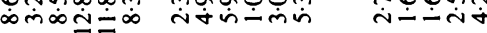

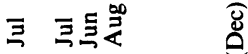

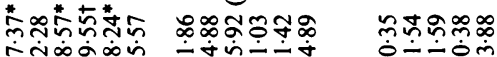

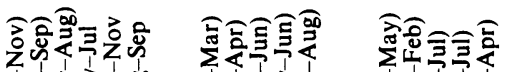

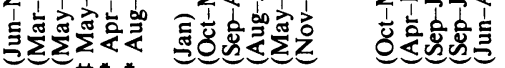

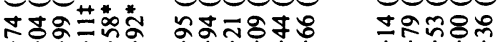

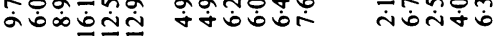

DOONTO - -NMOO DOONM

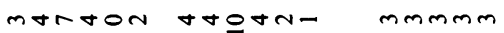

ormaman torn-n

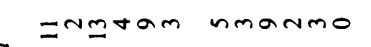

$\operatorname{tand}$

$\forall \nabla m m \nabla$

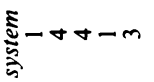

o

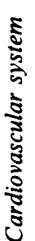

oogtua bNanno

o욤on n-mona

Q000m- manoon

anonnen m-nmoto

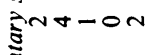

○

胥二 ర్ષ

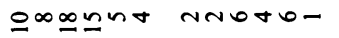

aogmma o-r-ne

으뭉 nmo-om

mornn

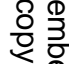

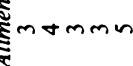

$n-n-\infty$

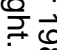

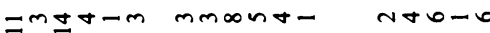

tuarmm arma-D mom-a

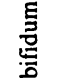

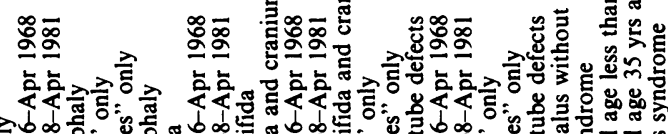

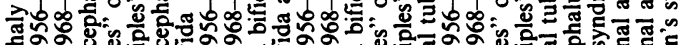
젼은

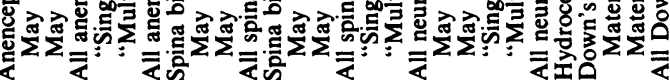
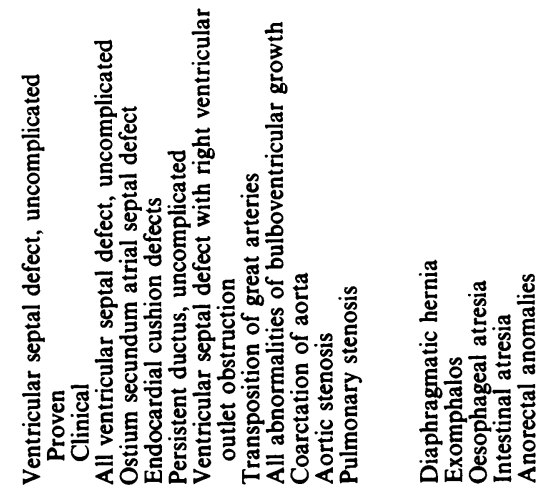
$\Xi$

这

ดั

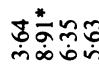

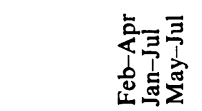

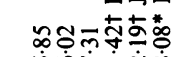

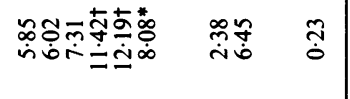

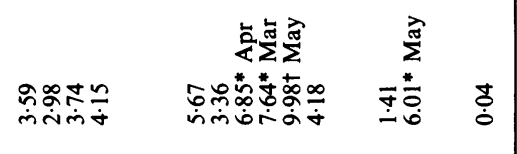

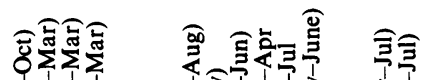

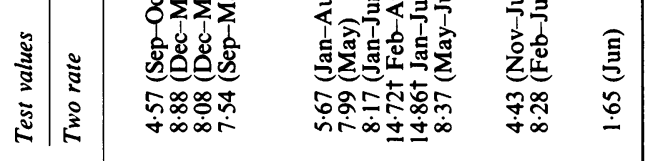

ทีลัก 므유 $+\infty$ or$-$

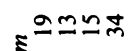

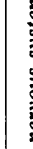

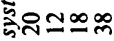
ํㅗㄴ $\square \infty$ 에 $\overline{\mathrm{s}}=990$ 约 ษェะ์ ungona da $\infty$

రW

芛 음 这血

음 $\frac{10}{3}$

흠요

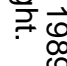

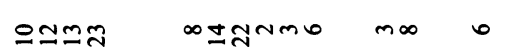

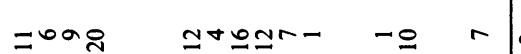
뜌 armaro mo = Iニสก

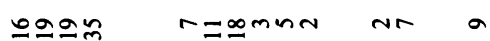

$\bar{O}$

일

T)

$\stackrel{\varrho}{\stackrel{2}{5}}$

$\overrightarrow{\vec{F}}$

흘

$\stackrel{\mathbb{8}}{2}$

क

$\overrightarrow{0}$

$\overrightarrow{\vec{\omega}}$

号

फे

$\rightarrow$

i

$\overrightarrow{8}$

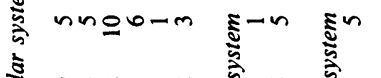

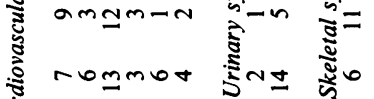

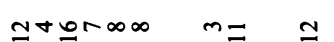

ర్ల

일

흥

\%

$\stackrel{\mathbb{2}}{2}$

훅

韋

बำ

ํำ

을

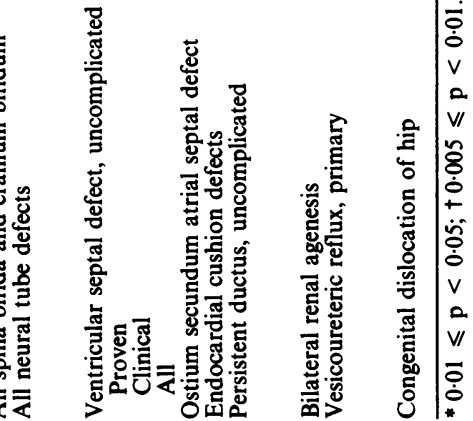


Table 4 Selected years of hospital births to Fylde residents by month of last menstrual period (LMP) and month of birth, and all births 1959 and 1960, by month of birth

\begin{tabular}{|c|c|c|c|c|c|c|c|c|c|c|c|c|}
\hline & Jan & $\mathrm{Feb}$ & Mar & Apr & May & Jun & $J u l$ & Aug & Sep & $O c t$ & Nov & Dec \\
\hline \multicolumn{13}{|c|}{ Month of LMP (hospital births) } \\
\hline $\begin{array}{l}1959 \\
1960 \\
1965 \\
1969 \\
1976 \\
1979 \\
1980 \\
1981\end{array}$ & $\begin{array}{r}97 \\
116 \\
147 \\
116 \\
175 \\
291 \\
250 \\
253\end{array}$ & $\begin{array}{l}100 \\
112 \\
125 \\
149 \\
160 \\
225 \\
221 \\
237\end{array}$ & $\begin{array}{r}91 \\
111 \\
160 \\
139 \\
166 \\
228 \\
254 \\
242\end{array}$ & $\begin{array}{r}105 \\
91 \\
147 \\
142 \\
176 \\
198 \\
257 \\
230\end{array}$ & $\begin{array}{r}95 \\
110 \\
137 \\
137 \\
184 \\
214 \\
251 \\
257\end{array}$ & $\begin{array}{l}107 \\
112 \\
154 \\
138 \\
192 \\
225 \\
258 \\
257\end{array}$ & $\begin{array}{r}97 \\
113 \\
152 \\
142 \\
187 \\
237 \\
249 \\
249\end{array}$ & $\begin{array}{l}101 \\
120 \\
134 \\
160 \\
195 \\
249 \\
244 \\
238\end{array}$ & $\begin{array}{l}109 \\
102 \\
138 \\
142 \\
203 \\
228 \\
245 \\
237\end{array}$ & $\begin{array}{r}97 \\
115 \\
163 \\
142 \\
191 \\
246 \\
249 \\
235\end{array}$ & $\begin{array}{r}103 \\
83 \\
138 \\
132 \\
208 \\
196 \\
229 \\
233\end{array}$ & $\begin{array}{l}105 \\
123 \\
151 \\
161 \\
196 \\
250 \\
268 \\
227\end{array}$ \\
\hline \multicolumn{13}{|c|}{ Month of birth (hospital births) } \\
\hline $\begin{array}{l}1959 \\
1960 \\
1965 \\
1969 \\
1976 \\
1979 \\
1980 \\
1981\end{array}$ & $\begin{array}{r}101 \\
80 \\
154 \\
140 \\
171 \\
208 \\
274 \\
246\end{array}$ & $\begin{array}{r}89 \\
98 \\
128 \\
131 \\
179 \\
196 \\
268 \\
216\end{array}$ & $\begin{array}{l}113 \\
118 \\
157 \\
150 \\
197 \\
241 \\
257 \\
255\end{array}$ & $\begin{array}{r}95 \\
125 \\
147 \\
129 \\
178 \\
216 \\
249 \\
259\end{array}$ & $\begin{array}{l}110 \\
116 \\
127 \\
165 \\
206 \\
255 \\
245 \\
261\end{array}$ & $\begin{array}{r}94 \\
110 \\
148 \\
138 \\
195 \\
234 \\
239 \\
224\end{array}$ & $\begin{array}{l}119 \\
109 \\
163 \\
129 \\
204 \\
235 \\
261 \\
238\end{array}$ & $\begin{array}{r}91 \\
88 \\
151 \\
151 \\
203 \\
212 \\
230 \\
218\end{array}$ & $\begin{array}{l}113 \\
119 \\
138 \\
160 \\
189 \\
239 \\
242 \\
238\end{array}$ & $\begin{array}{r}94 \\
120 \\
145 \\
133 \\
177 \\
292 \\
281 \\
251\end{array}$ & $\begin{array}{r}93 \\
117 \\
138 \\
143 \\
157 \\
246 \\
211 \\
243\end{array}$ & $\begin{array}{r}95 \\
108 \\
150 \\
131 \\
177 \\
213 \\
218 \\
246\end{array}$ \\
\hline \multicolumn{13}{|c|}{ Month of birth (all births) } \\
\hline $\begin{array}{l}1959 \\
1960\end{array}$ & $\begin{array}{l}308 \\
266\end{array}$ & $\begin{array}{l}292 \\
309\end{array}$ & $\begin{array}{l}297 \\
322\end{array}$ & $\begin{array}{l}299 \\
314\end{array}$ & $\begin{array}{l}347 \\
337\end{array}$ & $\begin{array}{l}298 \\
306\end{array}$ & $\begin{array}{l}344 \\
317\end{array}$ & $\begin{array}{l}290 \\
271\end{array}$ & $\begin{array}{l}298 \\
329\end{array}$ & $\begin{array}{l}285 \\
356\end{array}$ & $\begin{array}{l}260 \\
330\end{array}$ & $\begin{array}{l}276 \\
314\end{array}$ \\
\hline
\end{tabular}

births in 1959 and 1960 were now examined using the monthly variation in all births as a correction factor. No significant effects were found.

Although no consistent pattern of seasonal variation was found, we considered it important to analyse the data both correcting for and not correcting for monthly last menstrual period or birth variation, and so the number of hospital births in the Fylde over the period 1979 to 1981 was used as a correction factor. These years were chosen to represent all births, since hospital births in this period constituted $92 \%$ of all births in the area.

Tables 2 and 3 also give the values for the test statistics for the three methods described earlier. The tests were carried out both on uncorrected data and on data corrected for monthly variations in all conceptions or births. In general, corrected and uncorrected values of the test statistics were similar and we therefore quote only the uncorrected values. For each malformation showing a statistically significant seasonal effect, the pattern of the effect found is also given. For the two rate model we give months of the high rate period; for the sin model the month corresponding to the peak of the sin curve, and for the sin squared test the months in which the fitted curve lies above the line of no seasonality. As an indication to other researchers, we also give the months (enclosed in parentheses) of high rate period for the two rate model even where there is no significant effect.

\section{ANENCEPHALY}

The only anencephaly data to show a significant effect on all three tests were the anencephaly "multiples" based on month of last menstrual period. The two rate and sin squared models show that the high period was November to May.

\section{SPINA BIFIDA AND CRANIUM BIFIDUM}

For data based on month of last menstrual period, significant seasonal effects were found for spina bifida and spina bifida plus cranium bifidum, both in the period May 1956-April 1968 and in the whole of the survey period. Spina bifida and cranium bifidum "singles" also showed a significant seasonal prevalence. All conditions and combinations of conditions showed a high rate during the period of March to May on both the two rate and the sin squared test. The lack of significance of the sin test for some of the above conditions shows the poor performance of this test in detecting short seasonal effects. Figure 3 shows the observed data and the three fitted models (uncorrected) for spina bifida and cranium bifidum "singles".

For data based on month of birth, only the sin squared test for spina bifida shows a significant result, with a peak between the months of December to February and a second smaller peak in June. The fact that the fitted sin squared function has two high peaks makes this difficult to interpret, and the significant values should be treated with caution. 


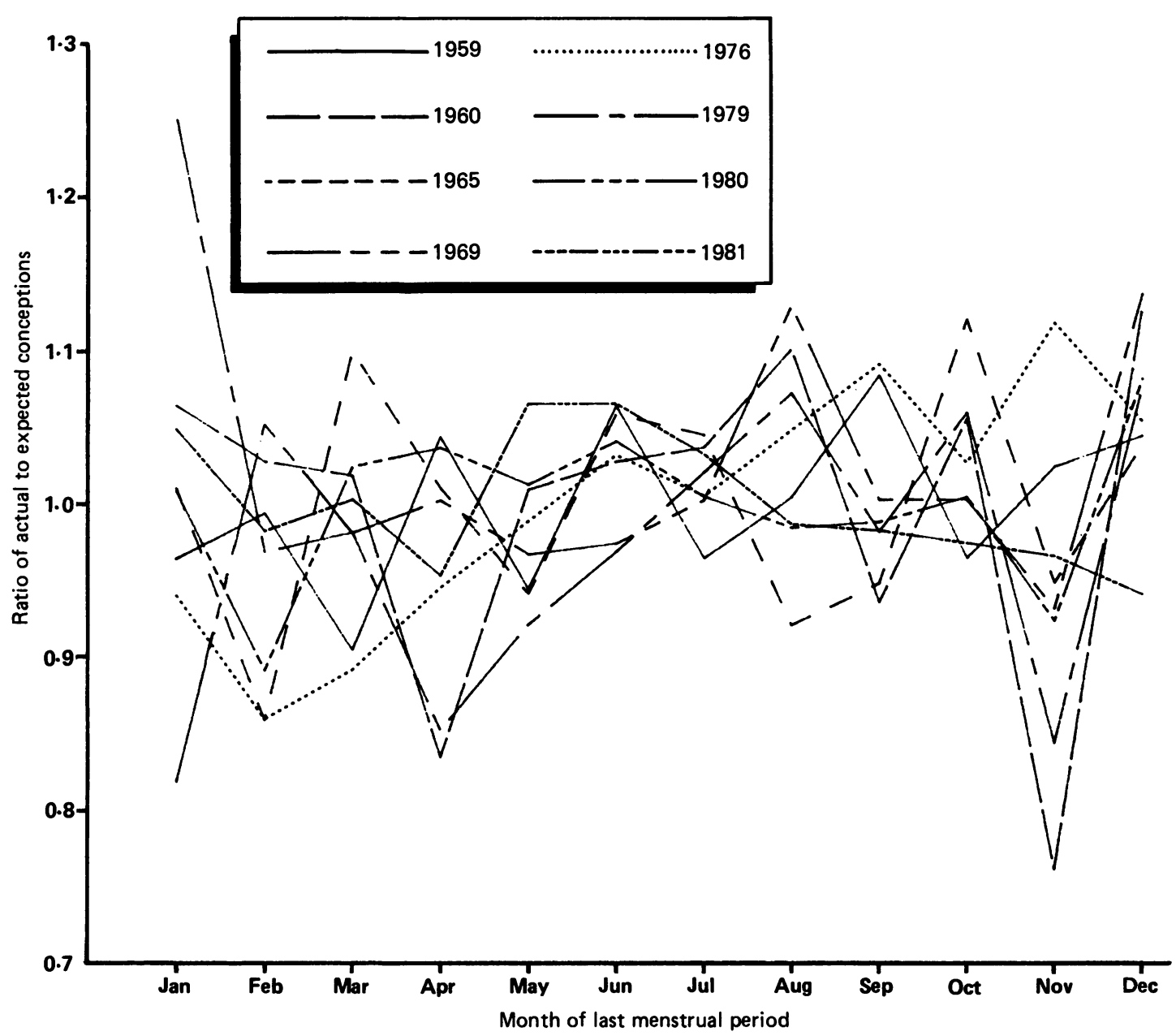

Fig 2 Monthly ratio of actual to expected conceptions of babies born in hospital in selected years

\section{ALL NEURAL TUBE DEFECTS}

Based on month of last menstrual period, the data for all neural tube defects, both for May 1956-April 1968 and for the complete study period, show a seasonal effect on all three tests. Neural tube defect "singles" showed a similar seasonal effect. The two rate and sin squared models give a high period of December-May for the May 1956-April 1968 period, and FebruaryMay for all neural tube defects and neural tube defect "singles". The December to May period was also significant for the latter two categories. There were no significant effects when the data were based on month of birth.

\section{CARDIOVASCULAR SYSTEM}

Both ostium secundum atrial septal defect and endocardial cushion defect showed strongly significant seasonal effects on data based both on last menstrual period and on date of birth, with a high last menstrual period rate in May to July for atrial septal defect, and in April or May to November for endocardial cushion defect. Significant summer seasonal effects, though not on all three tests, were also found for proven ventricular septal defects, all ventricular septal defects, and persistent ductus arteriosus. There is also some evidence in our data to suggest that all abnormalities of bulboventricular 

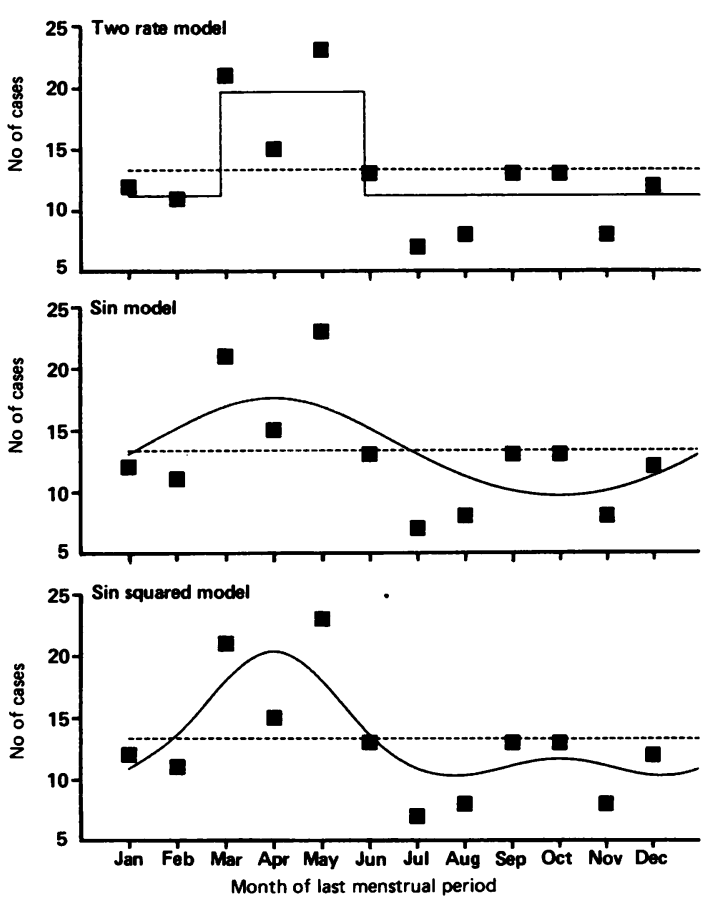

Fig 3 The three fitted models for numbers of spina bifida and cranium bifidum "singles" (no other major malformations) by month of last menstrual period.

growth have a higher rate in winter when classified by month of last menstrual period, with a peak in December on the sin test just failing to reach standard levels of significance $(p=0.052)$. When month of birth was considered, no significant seasonal effect was shown for proven ventricular septal defect, and seasonal effects, although present for all ventricular septal defects and persistent ductus, were significant on only one of the three tests, making the evidence less strong.

\section{URINARY SYSTEM}

Two conditions produced significant results (though neither on all three tests) when the data was classified by month of last menstrual period.

For bilateral renal agenesis, the two rate model produced a high period from March to October. Examination of the data for this condition reveals that the low winter period of four months produced only one case, compared with 28 for the 8 month summer period. The two rate model is better able to fit this type of data than the smooth sin and sin squared models, explaining the lack of significance of the latter two tests.
For vesicoureteric reflux, the sin and sin squared tests were both significant, with a seven month period from April to October being identified by the sin squared model and a peak of August identified by the sin model. The two rate model fits the data less adquately than a smooth function for this condition.

\section{Discussion}

\section{ASCERTAINMENT}

The greatest problem in epidemiological studies of congenital malformations is adequate ascertainment of cases. The success of a malformations registry has been stated to depend in part on the constant activity of one enthusiastic individual who runs it. ${ }^{5}$ Ascertainment is facilitated if this person is a single handed paediatrician working in a well circumscribed area served by one district general hospital and 50 miles from the nearest university referral centre. Then the vast majority of major malformations will be seen during his routine daily clinical practice.

Collaboration with a pathologist interested in paediatric and especially perinatal pathology is essential, so that lesions are not missed, particularly in stillbirths, and for accurate diagnosis. A very high necropsy rate is mandatory. Stillbirth and death certificates, with their well known inaccuracies in diagnoses, ${ }^{22}$ are used only to identify cases not examined by the pathologists, so that any available information about these babies can be obtained from their medical attendants or midwives.

This was the situation in the Fylde for the first 17 years of this study and led us to conclude that ascertainment was as complete as it is possible to get in practice. This conclusion was not altered in the last eight years when a second paediatrician cooperated fully with the study. Support for our claim was obtained where it was possible to compare our prevalence rates with others' findings, as we were able to do for example for congenital heart disease. $^{6}$

\section{SEASONAL VARIATIONS}

A seasonal prevalence for a malformation seems to indicate an environmental factor in aetiology. Certainly for anencephaly a study in Birmingham ${ }^{23}$ suggested that the seasonal prevalence could not be explained by fluctuation either in the conception rate of mothers or in abortion of affected embryos.

Time of conception is crucial to the search for environmental aetiological factors. For this reason month of maternal last menstrual period was used in this study. With date of birth, errors may occur because of varying gestations. 
We have shown that a seasonal variation for neural tube defects, which was significant when month of last menstrual period was used, was not significant when date of birth for the same cases was substituted. Cases of spina bifida alone showed a seasonal prevalence with month of last menstrual period and also with month of birth in one of the three tests used. The masking effect from using date of birth in the whole group appeared to be due mainly to the anencephaly component. This resulted from a greater variation in gestation in anencephaly, with $74 \%$ under 37 weeks compared with $13 \%$ for spina bifida.

The study of anencephaly and spina bifida by the Office of Population Censuses and Surveys ${ }^{24}$ tried to overcome this difficulty by using an estimated last menstrual period based on the percentage distribution of pregnancy duration for stillborn cases. However, in our series slightly less than a quarter of cases of spina bifida were stillborn and $71 \%$ of these had gestations of 37 weeks or over compared with $91 \%$ in live births. Therefore use of the distribution of gestations in stillbirths for estimating month of last menstrual period for all cases may have distorted the OPCS results.

Concealment of a significant seasonal prevalence by not using date of last menstrual period could be seen with other system lesions, for example in cases of proven ventricular septal defect and bilateral renal agenesis. However for most cardiac lesions a significant seasonal variation shown by month of last menstrual period was also revealed by date of birth.

In this paper we have confined ourselves to showing which major malformations have evidence of seasonal variations and have not tried to identify possible environmental factors.

\section{CENTRAL NERVOUS SYSTEM LESIONS}

From May 1956 to April 1968, when the prevalence of neural tube defects was high in the Fylde, conceptions of anencephaly were more common although not significantly so, in the six months December to May. This was a wider spread than the peak months of February to April reported for England and Wales ${ }^{24}$ using estimated last menstrual period. In the same period in the Fylde conceptions of spina bifida and cranium bifidum were significantly more common in March to May. This was a month earlier than, but of the same duration as, the peak national figures of April to June. Thus our findings for this period were essentially similar to the national figures for 1964 to 1972.

After 1967 the fall in prevalence of neural tube defects in the Fylde was associated with increasing summer hardness of the drinking water. ${ }^{21}$ This fall occurred particularly in the months December to
August so that the significant seasonal variations disappeared. The appearance of a low number of cases in June to August was not statistically significant, perhaps due to the fall in total numbers.

In an American study of neural tube defects ${ }^{9}$ only "singles" showed the well known epidemiological characteristics. No seasonal variations were found in either "singles" or "multiples", but only date of birth was analysed. Our study, using maternal last menstrual period, showed a significant seasonal variation in all neural tube defects considered together for "singles", but not for "multiples". Spina bifida and cranium bifidum gave a similar picture, but with anencephaly it was "multiples" which showed the significant variation. A seasonal prevalence is one of the epidemiological characteristics of neural tube defects, but our findings show that it is not invariably confined to "singles".

A seasonal prevalence for Down's syndrome has been shown by some investigations ${ }^{25} 26$ but not others. ${ }^{27}$ Although we found fewer cases with maternal last menstrual period in November to January the figures were not significant, either when the mother was aged 35 years and over, or with younger mothers. We offer no support for those who have suggested that seasonality plays a part in the aetiology of Down's syndrome.

Uncomplicated congenital hydrocephalus was far less common than hydrocephalus with spina bifida and our low numbers showed no significant seasonal variation.

\section{CARDIOVASCULAR SYSTEM LESIONS}

The prevalence of congenital heart disease has been reported to be highest in winter births ${ }^{7}$ or summer conceptions. ${ }^{6}$ Now we have shown that the excess of conceptions in summer was due mainly to three of the commonest types of heart lesion, uncomplicated proven ventricular septal defect, atrial septal defect and endocardial cushion defect. It may be relevant that these lesions share a common basis of incomplete septation of the heart at some stage of development. These findings for septal defects receive some support from a population survey in South Wales. ${ }^{28}$

Clinical ventricular septal defect also showed a tendency to more conceptions in summer, although not significantly so. The less strong seasonal variation could suggest that a different aetiological factor was more important for smaller defects. Alternatively and more likely, some clinical diagnoses could be wrong, although care was taken in the differential diagnosis, particularly from non-specific, transient systolic murmurs.

An additional contribution to the excess of summer conceptions was provided by persistent ductus arteriosus, another common lesion. This condition 
showed a significant increase of conceptions in late summer, boys and girls contributing almost equally to the total. There was a corresponding peak in births from May to July, which was earlier than a previously reported peak in affected girls from August to November. ${ }^{3}$ Four infants in our series had persistent ductus arteriosus due to maternal rubella, three being conceived in late winter or spring. The late summer peak may result from infections of a different virus.

In contrast to the findings for septal defects were those for another group of lesions which have been classified as showing abnormalities of bulboventricular growth. ${ }^{29}$ These are ventricular septal defect with right ventricular outflow obstruction, including Fallot's tetralogy, double outlet right ventricle and transposition of the great arteries. This group, the commonest cause of cyanotic congenital heart disease, showed its lowest prevalence from May to August. The figures did not reach statistical significance but contrasted sharply with the findings for septal defects. An excess of winter conceptions was shown by both transposition of the great arteries and ventricular septal defect with right ventricular outflow obstruction. The latter finding is supported by the report from Liverpool $^{8}$ of a significant excess of infants with Fallot's tetralogy conceived from January to June.

A seasonal prevalence for coarctation of the aorta has been reported, with an excess of boys born in March and April, ${ }^{3}$ while another hospital series showed two peaks. ${ }^{30}$ Our menstrual period data showed no seasonal variations, even for boys alone.

An excess of boys with pulmonary valvular stenosis born from July to September has also been noted. ${ }^{3}$ The Fylde had a low prevalence of isolated pulmonary stenosis $^{6}$ and our small numbers did not show a significant seasonal variation.

\section{ALIMENTARY SYSTEM LESIONS}

A summer excess of births for abnormalities of the lower gut and a winter excess for oesophageal atresia, but not tracheo-oesophageal fistula, has been reported. ${ }^{31}$ We did not show a significant seasonal prevalence in month of last menstrual period for anorectal anomalies (rectal agenesis, ectopic anus and covered anus), oesophageal atresia including tracheooesophageal fistula or any other major alimentary malformation.

\section{URINARY SYSTEM LESIONS}

In published reports a seasonal variation in prevalence has not been a noted feature of urinary tract lesions.

In the Fylde bilateral renal agenesis was significantly decreased in babies conceived in November to February. This finding was strengthened by the fact that ascertainment should have been complete. Cases are stillborn or fatal within two days of birth and very unlikely to have been missed with a $93 \%$ necropsy rate for perinatal deaths.

Primary vesicoureteric reflux was revealed by cystourethrography but was also diagnosed in children with renal scarring in whom reflux could no longer be demonstrated. In the Fylde, cases of primary vesicoureteric reflux showed a significant excess of conceptions from April to October. This finding must be treated with reserve as the degree of ascertainment is unknown. Cases will be recognised only if a urinary tract infection occurs and is managed correctly, ${ }^{32}$ or if a baby is investigated because of a family history of reflux.

No other common urinary tract malformation showed a significant seasonal variation.

\section{SKELETAL SYSTEM LESIONS}

We did not keep records of some common limb malformations such as talipes because we could not ensure adequate ascertainment.

Facial clefts were analysed from 1961, after which the vast majority of cases were seen before referral to surgeons. Our recorded prevalence was similar to that reported from nearby Liverpool over a comparable period. ${ }^{33}$ In Birmingham ${ }^{34}$ a significant seasonality for cleft lip was shown using month of birth, but was not confirmed at Oxford. ${ }^{35}$ In Sweden ${ }^{36}$ a seasonal variation was found for cleft palate and cleft lip with or without cleft palate using calculated last menstrual period, but not with birth date. In Liverpool ${ }^{33}$ there was a trend towards conception of babies with cleft palate in the second half of the year, but this was significant for girls only.

We found no significant seasonal prevalence in month of last menstrual period for cleft lip with or without cleft palate, or for isolated cleft palate.

In the 1950s an excess of births of babies with congenital dislocation of the hip in winter was reported. ${ }^{31}{ }^{34}$ However, we found no suggestion of a seasonal variation whether using date of birth or of last menstrual period.

We thank Drs D S Harry, S Murray and K S Vasudev, Consultant Pathologists, for their interest in paediatric necropsies; Drs W F W E Logan and J S Wright, Consultant Cardiologists, for their help, especially in classifying cardiac cases; and $\operatorname{Dr} \mathrm{C} \mathrm{J}$ Woods, Consultant Paediatrician, for his cooperation after 1973. We are grateful to Profs A Mercer and $M$ Aitkin of the University of Lancaster for advice and encouragement, and also to Prof $\mathrm{J} A$ Davis of the University of Cambridge for his support. 
Address for correspondence and reprints: Dr J P Bound, Department of Paediatrics, Victoria Hospital, Blackpool FY3 8NR, UK.

\section{References}

${ }^{1}$ McKeown T, Record RG. Seasonal incidence of congenital malformations of the central nervous system. Lancet 1951; i: 192-6.

2 Jolly H, Levene MI. Diseases of children. 5th ed. Oxford: Blackwell Scientific Publications, 1985: 133.

${ }^{3}$ Campbell M. Causes of malformations of the heart. $\mathrm{Br}$ Med J 1965; ii: 895-904.

${ }^{4}$ Laurence KM, Carter CO, David PA. Major central nervous system malformations in South Wales. Br J Prev Soc Med 1967; 21: 146-60.

${ }^{5}$ Hay JD. Population and clinic studies of congenital heart disease in Liverpool. Br Med J 1966; ii: 661-7.

${ }^{6}$ Bound JP, Logan WFWE. Incidence of congenital heart disease in Blackpool 1957-1971. Br Heart J 1977; 39: 445-50.

${ }^{7}$ Feldt RH, Avasthey P, Yoshimasu F, Kurland LT, Titus JL. Incidence of congenital heart disease in children born to residents of Olmsted County, Minnesota, 1950-1969. Mayo Clin Proc 1971; 46: 794-9.

${ }^{8}$ Kenna AP, Smithells RW, Fielding DW. Congenital heart disease in Liverpool: 1960-69. Q J Med 1975; 43: 17-44.

${ }^{9}$ Khoury MJ, Erickson JD, James LM. Etiologic heterogeneity of neural tube defects: clues from epidemiology. Am J Epidemiol 1982; 115: 538-48.

${ }^{10}$ International Society of Cardiology. Classification of heart disease in childhood. Groningen: VRB Offsetdrukkerij, 1970.

${ }^{11}$ Becker AE, Anderson RH. Pathology of congenital heart disease. London: Butterworths, 1981: 353.

12 Edwards JH. The recognition and estimation of cyclic trends. Ann Hum Genet 1961; 25: 83-7.

${ }^{13}$ Hewitt D, Milner J, Csima A, Pakula A. On Edwards' criterion of seasonality and non-parametric alternative. Br J Prev Soc Med 1971; 25: 174-6.

14 Walter SD, Elwood JM. A test for seasonality of events with a variable population at risk. Br J Prev Soc Med 1975; 29: 18-21.

${ }^{15}$ St Leger AS. Comparison of two tests of seasonality in epidemiological data. Appl Statist 1976; 25: 280-6.

${ }^{16}$ Roger JH. A significance test for cyclic trends in incidence data. Biometrika 1977; 64: 152-5.

${ }^{17}$ Nam J. Efficient method for identification of cyclic trends in incidence. Commun Statist Theor Meth 1983; 12: 1053-68.

18 McCullagh P, Nelder JA. Generalised linear models. London: John Wiley, 1983.
${ }^{19}$ Sandahl B. Seasonal Incidence of some congenital malformations in the central nervous system in Sweden 1965-1972. Acta Paediatr Scand 1977; 66: 65-72.

${ }^{20}$ Baker R, Clarke MRB, Francis B, et al. The GLIM system release 3.77 Users' Guide. 2nd ed. Oxford: Numerical Algorithms Group, 1986.

${ }^{21}$ Bound JP, Harvey PW, Brookes DM, Sayers BMcA. The incidence of anencephalus in the Fylde peninsula 1956-76 and changes in water hardness. $J$ Epidemiol Community Health 1981; 35: 102-5.

22 Emery JL, Irvine KA. Death certification of children. $\mathrm{Br}$ Med J 1958; ii: 1510-2.

${ }^{23}$ Leck I, Record RG. Seasonal incidence of anencephalus. Br J Prev Soc Med 1966; 20: 67-75.

${ }^{24}$ Rogers SC, Weatherall JAC. Anencephalus, spina bifida and congenital hydrocephalus. England and Wales 19641972. Office of Population Censuses and Surveys. Studies on Medical and Population Subjects No. 32. London: HMSO, 1976.

${ }^{25}$ Leck I. Incidence and epidemicity of Down's syndrome. Lancet 1966; ii: 457-60.

${ }^{26}$ Harlap S. A time-series analysis of the incidence of Down's syndrome in West Jerusalem. Am J Epidemiol 1974; 99: $210-7$.

${ }^{27}$ Mikkelsen M. Epidemiology of trisomy 21: population, peri- and antenatal data. Hum Genet 1981; 2: 211-26.

${ }^{28}$ Roberts CJ, Lowe CR, Lloyd S. Cyclic variations in date of last menstrual period of mothers of infants with congenital malformations in South Wales, 1964-66. Br J Prev Soc Med 1972; 26: 212-8.

${ }^{29}$ Anderson RH, Ashley GT. Growth and development of the cardiovascular system: anatomical development. In: Davis JA, Dobbing J, eds. Scientific foundations of paediatrics. London: William Heineman, 1974: 165-98.

${ }^{30}$ Miettinen OS, Reiner ML, Nadas AS. Seasonal incidence of coarctation of the aorta. Br Heart $J$ 1970; 32: 103-7.

${ }^{31}$ Slater BCS, Watson GI, MCDonald JC. Seasonal variation in congenital abnormalities. Br J Prev Soc Med 1964; 18: $1-7$.

32 White RHR. Management of urinary tract infection. Arch Dis Child 1987; 62: 421-7.

${ }^{33}$ Owens JR, Jones JW, Harris F. Epidemiology of facial clefting. Arch Dis Child 1985; 60: 521-4.

${ }^{34}$ Edwards JH. Seasonal incidence of congenital disease in Birmingham. Ann Hum Genet 1961; 25: 89-93.

${ }^{35}$ Fraser GR, Calnan JS. Cleft lip and palate: seasonal incidence, birth weight, birth rank, sex, site, associated malformations and parental age. Arch Dis Child 1961; 36: 420-3.

${ }^{36}$ Sandahl B. Seasonal incidence of cleft lips and cleft palates in Sweden, 1965-1974. Scand J Plast Reconstr Surg 1977; 11: $39-43$.

Accepted for publication April 1989. 